\title{
Paisagem Cultural e Sustentabilidade: possíveis conexões e subsídios para políticas públicas e planejamento do turismo
}

\author{
Cultural Landscape and Sustainability: possible connections and subsidies for public \\ policies and planning of tourism
}

\section{Paisaje Cultural y Sostenibilidad: posibles conexiones y subsidios para políticas públicas y planificación del turismo}

\author{
Beatriz Veroneze Stigliano ${ }^{1}$ \\ Helena Ribeiro ${ }^{2}$ \\ Pedro de Alcântara Bittencourt César ${ }^{3}$
}

\section{Resumo}

Busca-se estabelecer um panorama conceitual acerca da paisagem cultural, especialmente pela abordagem da Geografia Cultural. Considera-se que a organização social do mundo expressa processos subjetivos e materiais. Nesse sentido, uma paisagem cultural remete ao 'conteúdo' de uma área, abrangendo um grupo humano, as ações por ele desenvolvidas, um determinado conjunto de circunstâncias naturais e as modificações refletidas no ambiente. Agrega-se à reflexão a noção de sustentabilidade na atividade turística. Enfocam-se diferentes dimensões da sustentabilidade, destacando a possível contribuição do conceito de paisagem cultural no processo de tomada de decisão e desenvolvimento do turismo. Deste modo, baseando-se em pesquisa bibliográfica de materiais referenciais, discutem-se fundamentos para uma possível construção teórica engendrando os referidos termos. Apresentam-se, por fim, conexões e subsídios para pesquisas e projetos voltados ao desenvolvimento de políticas públicas e planejamento no âmbito do turismo sustentável.

Palavras-chave: paisagem cultural; sustentabilidade; turismo; planejamento; políticas públicas.

\footnotetext{
${ }^{1}$ Bacharel em Turismo, Mestre em Ciências da Comunicação e Doutora em Ciência Ambiental pela Universidade de São Paulo; Mestre em Leisure and Environments pelo WICE/Wageningen University. Professora adjunta da Universidade Federal de São Carlos, campus Sorocaba. E-mail: biatur@usp.br.

${ }^{2}$ Geógrafa, Mestre pela Universidade da Califórnia Berkeley, Doutora e Livre-docente pela USP. Professora Titular do Departamento de Saúde Ambiental da Faculdade de Saúde Pública e do Programa de Ciências Ambientais da Universidade de São Paulo. E-mail: lena@usp.br.

${ }^{3}$ Arquiteto e Urbanista; Doutor em Geografia pela Universidade de São Paulo. Professor titular do Centro de Artes e Arquitetura e do Programa de Mestrado em Turismo da Universidade de Caxias do Sul. E-mail: pabcesar@ucs.br.
} 


\begin{abstract}
This study sets out to establish a conceptual perspective on cultural landscape, especially from the Cultural Geography frame of reference. The social organization of the world expresses subjective and material processes. A cultural landscape refers, thus, to the 'content' of an area covering a human community and its actions, a certain set of natural circumstances and the changes reflected on the environment. The notion of sustainability in tourism is added to the analysis. Different dimensions of sustainability are focused, highlighting the possible contribution of cultural landscape in the decision making and tourism development process. Thus, based on literature review, the discussion underscores possible basis for a theoretical construction engendering such terms. Therefore, it presents subsidies for research and projects focusing on planning and public policies for sustainable tourism.
\end{abstract}

Keywords: cultural landscape; sustainability; tourism; planning; public policies.

\title{
Resumen
}

Se recoge establecer un panorama conceptual acerca del paisaje cultural, especialmente por el abordaje de la Geografía Cultural. Se considera que la organización social del mundo expresa procesos subjetivos y materiales. Un paisaje cultural remite, de esa forma, al 'contenido' de un área, comprendiendo una comunidad humana, las acciones por ella desarrolladas, un determinado conjunto de circunstancias naturales y las modificaciones propiciadas por las prácticas del grupo sobre el ambiente. Se agrega a la reflexión la noción de sostenibilidad en la actividad turística. Se enfocan diferentes dimensiones de la sostenibilidad, destacando la posible contribución del concepto de paisaje cultural en el proceso de toma de decisiones y desarrollo del turismo. De este modo, basándose en investigación bibliográfica de materiales referenciales, se discuten fundamentos para una posible construcción teórica engendrando los referidos términos. Se presentan, así, subsidios para investigaciones, encuestas y proyectos vueltos al desarrollo de políticas públicas y planificación en el ámbito del turismo sostenible.

Palabras-clave: paisaje cultural; sostenibilidad; turismo; planificación; políticas públicas.

\section{Introdução}

A superfície terrestre passa por aceleradas transformações, nas últimas décadas, devido às mais diversas causas: intervenções urbanas, produção agrícola, atividades turísticas, mudanças climáticas, entre outras. Concomitantemente, verifica-se uma perplexidade quanto à alteração das paisagens por elas geradas. Um desafio epistemológico que se coloca é a 


\section{TURISMO EM ANÁLISE}

integração entre ambiente natural e cultura, para o que se analisam, neste estudo, os conceitos de paisagem e de paisagem cultural (CLAVAL, 1999; WAGNER; MIKESELL, 2000; COSGROVE, 2004), como fundamentos de reflexões.

Baseando-se em pesquisa bibliográfica, este trabalho estabelece, assim, um panorama conceitual acerca da paisagem cultural, especialmente pelo viés da geografia cultural. Agregase, a ele, a abordagem da noção de sustentabilidade na atividade turística. Busca-se, desse modo, discutir bases para uma possível construção teórica engendrando os referidos termos. Tem-se como objetivo gerar reflexões que tragam contribuições para o desenvolvimento de ações de planejamento e políticas públicas participativas, voltadas ao turismo, que se baseiem em conceitos de paisagem cultural e de sustentabilidade.

\section{Origens e Significados do Termo Paisagem}

A paisagem apresenta-se carregada de símbolos, significados, marcas visíveis ou ocultas. Suas origens etimológicas remetem ao termo latino pagus. Em italiano, o substantivo pàgo faz referência aos distritos civis ou religiosos definidos na Roma antiga (MILANI, 2007). Na Itália, o ambiente idílico e pastoril de colinas e riachos cobertos de trigais era conhecido como parerga e constituía os cenários auxiliares dos temas comuns da mitologia clássica e das escrituras sagradas (SCHAMA, 1996). O italiano transcreve a idéia de extensão de pays, criando paesaggio, de onde deriva o vocábulo em francês. Seu emprego é verificado a partir de 1549 (CLAVAL, 2004). Dos Países Baixos, veio a palavra landschap que, como sua raiz germânica, Landschaft, tinha o duplo significado de "unidade de ocupação humana - uma jurisdição - e de qualquer coisa que pudesse ser o aprazível objeto de uma pintura" (SCHAMA, 1996). O termo landscape impõe-se com a difusão de um novo gênero pictural.

Holzer (1999) confirma a associação de áreas amplas com características físicas e culturais homogêneas com a paysage, reforçada por Vidal de La Blache, tem sua origem no radical pays, que significava, na Idade Média francesa, simultaneamente, habitante e território. A escola francesa logo se apropriou da palavra paysage, destituindo-a de seu sentido renascentista e restituindo o sentido mais amplo de seu correlato alemão. No âmbito 


\section{TURISMO EM ANÁLISE}

lingüístico, destacam-se questões como, por exemplo, se Landschaft equivale a paysage. A palavra alemã é "mais antiga, medieval, seu conteúdo é mais abrangente e mais complexo que o das línguas latinas, em que o termo é renascentista, já limitado, em sua origem, às artes plásticas" (HOLZER, 1999, p.152). Por sua vez, de acordo com Cosgrove (2004), teria surgido no Renascimento para indicar uma nova relação entre os seres humanos e seu ambiente. A época foi marcada pela aplicação de regras formais, matemáticas e geométricas, derivadas de Euclides.

A paisagem, destarte, está intimamente ligada a uma nova maneira de ver o mundo como uma criação racionalmente ordenada, designada e harmoniosa, cuja estrutura e mecanismo são acessíveis à mente humana e ao olho, e agem como guias para os seres humanos em suas ações de alterar e aperfeiçoar o meio ambiente. Algumas implicações desse conceito complexo são: (i) foco nas formas visíveis de nosso mundo, sua composição e estrutura espacial; (ii) unidade, coerência e ordem ou concepção racional do meio ambiente; (iii) a idéia de intervenção humana e controle das forças que modelam e remodelam nosso mundo (COSGROVE, 2004, p.99). Claval (2001) explica que alguns pesquisadores partiram da premissa de que a paisagem não é uma categoria universal do pensamento.

Destaca-se a subjetividade relacionada às paisagens, afinal, até as paisagens que "parecem mais livres de nossa cultura, a um exame mais atento, podem revelar-se como seu produto. Parece correto reconhecer que é nossa percepção transformadora que estabelece a diferença entre matéria bruta e paisagem" (SCHAMA,1996, p.20). Para este autor, nossa tradição da paisagem é produto de uma cultura comum. É, portanto, relativa a uma tradição construída a partir de um rico depósito de mitos e lembranças. As paisagens podem ser conscientemente concebidas para expressar as virtudes de uma determinada comunidade política ou social (SCHAMA, 1996). Berque (1998) complementa tal noção ao afirmar que a paisagem não reside no objeto, nem somente no sujeito, mas na complexa interação entre ambos.

Diferentes disciplinas acadêmicas, tais como Arquitetura, Antropologia, Ecologia e Geografia têm a paisagem como objeto e tema de estudos. Há um denominador comum entre elas, mas cada uma se apropria do conceito de uma maneira própria, conferindo-lhe significados 


\section{TURISMO EM ANÁLISE}

bastante diversos. Internamente, cada área do conhecimento apresenta correntes de pensamento que tratam da paisagem, teórica e metodologicamente, de formas bastante distintas. Isso torna a noção de paisagem extremamente polissêmica (RIBEIRO, 2007).

\section{A Paisagem e a Abordagem Cultural}

Os estudos da paisagem cultural têm, em suas origens, Carl Sauer como grande expoente. Seu grande clássico, “A morfologia da paisagem”, publicado em 1925, é pioneiro da geografia cultural. Nele, Sauer defende que a cultura é apreendida através da análise das técnicas, dos utensílios e das transformações das paisagens, ou seja, dos aspectos materiais, utilizados pelo homem de forma a modificar o ambiente natural. Sauer é considerado fundador da chamada Escola de Berkeley, que tem alguns discípulos de relevância, em termos de produção. Desses, Philip L. Wagner e Marvin W. Mikesell, entre outros, desenvolveram, nessa Universidade da Califórnia, campus de Berkeley, sua base de pesquisa (CORRÊA; ROSENDAHL, 2000).

Características principais da obra saueriana, segundo Corrêa e Rosendahl (2000, p.9), são: a crença na diversidade cultural, a ênfase no passado, a valorização da contingência, o primado da compreensão, uma certa postura anti-urbana e o privilégio de sociedades tradicionais. Ressaltam a influência do antropólogo Alfred Kroeber, colega de Berkeley, na obra de Sauer. Em texto originalmente escrito em 1931 e re-editado em 2000, Sauer afirma que a geografia cultural implica um programa integrado ao objetivo geral da geografia, qual seja: "um entendimento da diferenciação da Terra em áreas. Seu método é evolutivo, especificamente histórico até onde a documentação permite e, por conseguinte, trata de determinar as sucessões de cultura que ocorreram numa área" (SAUER, 2000, p.109-10).

Afirma Holzer (1999) que, da década de 1920 até o início de 1960, o objetivo da Geografia Cultural era estabelecer bases metodológicas que atendessem a seu variado programa de estudos. A partir de 1960, a ênfase no caráter coletivo da cultura é deixada de lado e preocupações eminentemente epistemológicas direcionam os estudos para o estado das atitudes e preferências que, segundo o próprio Sauer, podiam ser inventadas ou adquiridas. 


\section{TURISMO EM ANÁLISE}

Uma grande mudança de atitudes caracteriza a transformação que começa a afetar os estudos culturais conduzidos a partir do início da década de 1970. Teve destaque, à época, a constatação de que as realidades que refletem a organização social do mundo, a vida dos grupos humanos e suas atividades jamais são puramente materiais. São expressão de processos cognitivos, de atividades mentais, de trocas de informação e de idéias. As relações dos homens com o meio ambiente e com o espaço têm dimensão psicológica e sociopsicológica. Nascem das sensações experimentadas e das percepções a elas ligadas (CLAVAL, 2001).

O ressurgimento da geografia cultural se faz em um "contexto pós-positivista e vem da consciência de que a cultura reflete e condiciona a diversidade da organização espacial e sua dinâmica. A dimensão cultural torna-se necessária para a compreensão do mundo" (CORRÊA, 1999). O ressurgir da geografia cultural é marcado por diversas influências: pela geografia cultural que a antecedia e pelo materialismo histórico e dialético, que considera a cultura como um reflexo e uma condição social, simultaneamente. Atualmente, valoriza-se a experiência, a intersubjetividade, os sentimentos, a intuição e a compreensão daquilo que não se repete (CORREA, 1999).

Nesse cenário, o lugar é tido como um conceito-chave da geografia, por Relph (1976) e Tuan (1980; 1983). As temáticas da religião, da percepção ambiental, da identidade espacial e a interpretação de textos (literatura, música, pintura e cinema) estão entre as que emergiram ou foram retomadas. $\mathrm{O}$ espaço urbano passa a ser objeto de interesse na geografia cultural. Esta “distingue, descreve e classifica os complexos típicos de aspectos ambientais, incluindo aqueles feitos pelo homem, que coincidem com cada comunidade cultural" (CORRÊA, 1999, p.53). Ao fazê-lo, considera-os como paisagens culturais e procura origens na história da cultura (WAGNER; MIKESELL, 2000). Entende-se que a cultura resulta da capacidade de os seres humanos se comunicarem entre si por meio de símbolos. Assim:

Quando as pessoas parecem pensar e agir similarmente, elas o fazem porque vivem, trabalham e conversam juntas, aprendem dos mesmos companheiros e mestres, tagarelam sobre os mesmos acontecimentos, questões e personalidades, observam ao seu redor, atribuem o mesmo significado aos 


\section{TURISMO EM ANÁLISE}

objetos feitos pelo homem, participam dos mesmos rituais e recordam o mesmo passado (WAGNER; MIKESELL, 2000, p.114-5).

Refletem, dessa forma, a existência de símbolos e língua comuns. A paisagem passa a ser concebida em uma amplitude de abordagens, tendo por base uma matriz não-positivista. Ela desempenha um papel na aquisição, por cada um, de conhecimentos, atitudes e reflexos dos quais temos necessidade para viver: constitui o quadro em relação ao qual se aprende a se orientar; fala da sociedade na qual se vive e das relações que as pessoas estabelecem com a natureza. Esse aspecto se apresenta carregado de lembranças históricas cuja significação pode ser apreendida pelo observador atento. A paisagem é, assim, uma das matrizes da cultura. É, também, o lugar onde as atividades humanas gravam sua marca (CLAVAL, 1999).

Altera-se o foco e fundamentação ontológica da paisagem. Uma das principais mudanças incorre no fato de se buscar compreender como a vida dos indivíduos e dos grupos se organiza no espaço, nele se imprime e reflete (CLAVAL, 2001). Desse modo, "trabalha-se com a dialética das relações sociais no espaço, com sua ligação ao meio ambiente e ao papel complexo das paisagens, ao mesmo tempo suportes e matrizes das culturas" (CLAVAL, 2001, p.41). O próprio conceito de paisagem é uma forma especial de dar significados, estruturar e compor o mundo externo, "cuja história tem que ser entendida em relação à apropriação material da terra" (COSGROVE; JACKSON, 2000, p.18).

Berque (1998) apresentou importante contribuição ao entendimento da simbologia da paisagem. Este pesquisador aborda a geografia cultural como o estudo do sentido, tanto unitário como global, que a sociedade faz de sua relação com o espaço e a natureza, que, concretamente, é vista como paisagem.

A paisagem cultural refere-se, pois, ao conteúdo de uma determinada área ou um complexo geográfico de um certo tipo, no qual são manifestas as escolhas feitas e as mudanças realizadas pelos homens enquanto membros de uma comunidade cultural (WAGNER; MIKESELL, 2000). Seu estudo serve, simultânea e inseparavelmente, a diversos fins. Independente da sua função de descrição sistemática, proporciona uma base para a classificação regional, possibilita um insight sobre o papel do homem nas transformações do 


\section{TURISMO EM ANÁLISE}

espaço e esclarece certos aspectos da cultura e de comunidades culturais em si mesmas. A paisagem cultural, então, pode ser entendida como um produto concreto e característico da interação complicada entre uma determinada comunidade humana, abrangendo certas preferências e potenciais culturais, e um conjunto particular de circunstâncias naturais. Tratase de uma herança de um longo período de evolução natural e de muitas gerações de esforço humano (WAGNER; MIKESELL, 2000).

Ao reconstruir os conceitos de paisagem e de cultura com novas referências conceituais, os estudos recentes de geografia cultural enfatizam o caráter de construção cultural sofisticada do próprio conceito de paisagem. Esta passa a ser vista como um modo especial de compor, estruturar e dar significado a um mundo externo, cuja história tem que ser entendida em relação à apropriação material da terra. A paisagem pode, então, ser estudada por vários meios e superfícies: por intermédio da pintura sobre a tela, da escrita sobre o papel, das imagens gravadas em filme, e mesmo da terra, da pedra, da água e da vegetação sobre o solo. Esses meios revelam significados que os grupos humanos atribuem às áreas e lugares, permitindo relacionar esses significados a outros aspectos e condições da existência humana (COSGROVE; JACKSON, 2000). A linha interpretativa dentro da geografia cultural recente desenvolve a metáfora da paisagem como 'texto', a ser lido e interpretado como documento social.

Os signos de que as paisagens são portadoras transmitem mensagens intencionais, geralmente muito fáceis de serem decifradas pelas pessoas familiarizadas com a cultura local (CLAVAL, 2004). No entanto, a mensagem não se torna clara para os demais, a não ser que se conheçam os textos que ela procura transcrever. É ao papel que a paisagem desempenha nos processos culturais e aos valores que aí se lêem que os pesquisadores se atêm, nos últimos tempos (CLAVAL, 1999). Nesse sentido:

As paisagens tomadas como verdadeiras de nossas vidas cotidianas estão cheias de significados. Grande parte da geografia mais interessante está em decodificá-las. É tarefa que pode ser realizada por qualquer pessoa no nível de sofisticação apropriado para elas. Porque a geografia está em toda a parte, reproduzida diariamente por cada um de nós (COSGROVE, 2004, p.121). 


\section{TURISMO EM ANÁLISE}

Assim, revelar os significados na paisagem cultural exige a habilidade imaginativa de entrar no mundo dos outros de maneira auto-consciente e, então, re-apresentar essa paisagem num nível no qual seus significados possam ser expostos e refletidos (COSGROVE, 2004).

\section{Valores Culturais e o Ambiente Natural - rompendo fronteiras}

Abordando a emergência de uma nova geografia cultural, Cosgrove afirma que esta é parte de uma ampla resposta intelectual ao "colapso das fronteiras intelectuais herdadas dentro da academia, e a um trabalho crescente de flexibilidade teórica e empírica que alguns rotulariam de pós-moderna" (COSGROVE, 1999, p.19). Nos estudos culturais, continua, a história é substituída pelo passado, pela memória, e, então, trazida para sua íntima conexão com o presente e o futuro. As relações sociais da memória são poderosamente importantes na constituição da identidade e do lugar.

Atualmente, a geografia cultural comporta desde pesquisadores que estudam os padrões de objetos no espaço, sem referência ao processo cultural, até aqueles que investigam o processo cultural, sem referência ao espaço, ao lugar ou à paisagem. Afinal:

\footnotetext{
A concepção de geografia cultural enquanto heterotopia epistemológica é a melhor e devemos aceitar as implicações desta condição cada vez mais comum na academia. Uma parte importante desta aceitação é se dar conta de que um discurso 'dominante', capaz de estabelecer uma unidade intelectual, é ilusão. (...) o que temos, na realidade, são "lugares de diferença”", cada um dos quais com seu próprio discurso, ligados a outros lugares semelhantes dentro das ciências sociais e humanidades (DUNCAN, 2000, p.82).
}

Nessa 'nova' geografia, a cultura não é uma categoria residual, mas o meio pelo qual a mudança social é vivenciada, contestada e constituída. Além disso, a visão unitária da cultura dá lugar à pluralidade de culturas, cada uma com suas especificidades de tempo e lugar (COSGROVE; JACKSON, 2000). Para esses autores, a geografia das formas culturais é muito mais do que reflexo passivo das forças históricas que a moldaram. 


\section{TURISMO EM ANÁLISE}

O conceito de cultura, na prática antropológica moderna, sancionou uma "distinção entre cultura, compreendida como conjunto de valores e idéias, e interação social” (MERQUIOR, 1997, p.99), tendo muitos valores simbólicos como mediadores e sínteses. A cultura é constantemente reproduzida pelos seres humanos, em suas ações, muitas vezes rotineiras, da vida cotidiana. Ela é "capaz de ser trazida ao nível da reflexão consciente e da comunicação. [...] Assim, a cultura é, ao mesmo tempo, determinada por e determinante da consciência e das práticas humanas" (COSGROVE, 2004, p.101-2). Para compreender as expressões "impressas por uma cultura em sua paisagem, necessitamos de um conhecimento da 'linguagem' empregada: os símbolos e seu significado nessa cultura” (COSGROVE, 2004, p.105-6).

Reforça Mikesell (2000) que o estudo cultural não oferece a recompensa da certeza profética nem da simplificação grandiosa. As generalizações sobre a cultura são, na melhor das hipóteses, frágeis sínteses que devem ser construídas e desmontadas repetidamente.

Hoje, ao se pensar em cultura, faz-se necessário envolver as lógicas culturais e também as naturais. No entanto, encontra-se grande dificuldade teórica ao se buscar trabalhar em conjunto cultura e natureza, sobretudo em decorrência de, no pensamento moderno, esses dois campos pertencerem a domínios distintos. Devem ser dadas respostas a esta questão, pois o imperativo ecológico (CLAVAL, 2001) aparece com mais importância do que nunca por causa do risco da exploração exagerada dos ambientes (locais) e de se assistir à multiplicação de desequilíbrios globais. É preciso, pois, “explorar a conivência que se estabelece entre o espírito e o meio ambiente que o envolve" (CLAVAL, 2001, p.57).

\section{Aplicações do Conceito de Paisagem Cultural}

O conceito de paisagem cultural que tem sido utilizado pela United Nations, Educational, Scientific and Cultural Organization (UNESCO), desde a Convenção de 1972, caminha nessa direção. Assim, em 1992, ao instituir a paisagem cultural como categoria para inscrição de bens na lista de patrimônio mundial, deliberou-se a intenção de se libertar da imposição dos critérios existentes para a inscrição dos bens naturais ou culturais. As paisagens culturais são, assim, entendidas como: 
Ilustrativas da evolução da sociedade humana e seus assentamentos ao longo do tempo, sob a influência de contingências físicas e/ou oportunidades apresentadas pelo ambiente natural, bem como pelas sucessivas forças sociais, econômicas e culturais, externas e internas, que nelas interferem.

Elas devem ser selecionadas pelo seu valor universal e pela sua representatividade em termos de uma região geocultural claramente definida e também pela sua capacidade de ilustrar os elementos culturais essenciais e típicos dessa região. [...] O termo 'paisagem cultural' envolve uma diversidade de manifestações da interação entre a humanidade e seu ambiente natural (UNESCO, 1999, p.36-37).

Outro termo importante, nessa formulação, é o da ambiência. Reforça-se, na Recomendação de Nairobi (1976), uma definição acerca de como o quadro ao redor do bem protegido que influi na percepção do observador. Defende-se que cada conjunto histórico ou tradicional e sua ambiência deveria ser considerado em sua globalidade, como um todo coerente, cujo equilíbrio e caráter específico dependem da síntese dos elementos que o compõem e compreendem tanto as atividades humanas como as construções, a estrutura espacial e as zonas circundantes. Dessa maneira, todos os elementos válidos, incluídas as atividades humanas, desde as mais modestas, têm, em relação ao conjunto, uma qualidade, um significado, que é preciso respeitar (IPHAN, 2004).

Já se encontram casos concretos de propostas para a elaboração de Planos de Ordenamento Territorial que incorporam variáveis culturais ao planejamento do uso do solo, além das variáveis naturais. Nesse sentido, por exemplo, a Convenção Européia de Paisagem, elaborada em Florença, no ano 2000, direciona os critérios e as estratégias a serem adotadas para a conservação, recuperação e valorização da paisagem na Europa. Nela, defende-se a importância de se estar consciente "de que a paisagem contribui para a formação das culturas locais, e que é um componente fundamental do patrimônio natural e cultural, que contribui para o bem-estar dos seres humanos" (COUNCIL OF EUROPE, 2000, p.2). Ações envolvendo a paisagem cultural têm ganhado força com a iniciativa da UNESCO para fortalecer o conceito e pela busca por consolidá-lo através do reconhecimento de patrimônios que sejam representativos, ao mesmo tempo, por seus aspectos naturais e culturais. É reflexo de um esforço para superar a dicotomia comumente propagada. 


\section{TURISMO EM ANÁLISE}

O fortalecimento das discussões a respeito da paisagem cultural tem acontecido, no Brasil, especialmente, a partir deste século, ainda timidamente (STIGLIANO, 2009). A título de exemplo, pode-se citar a iniciativa desenvolvida, em 2007, com o Seminário 'Semana do Patrimônio - Cultura e Memória na Fronteira', organizado pelo Instituto do Patrimônio Histórico e Artístico Nacional (IPHAN). Neste evento, foi elaborada a "Carta de Bagé", ou "Carta da Paisagem Cultural”. Este documento apresenta a definição de paisagem cultural e algumas orientações sobre os procedimentos para sua preservação e a "certificação concedida pelos órgãos de patrimônio cultural [...] sob a forma de um termo de compromisso e de cooperação para gestão compartilhada de sítios de significado cultural” (IPHAN, 2007, p.3).

No turismo, descortinam-se novas possibilidades a partir da paisagem cultural. Entre outras questões, coloca-se como uma oportunidade, especialmente, junto àqueles desinteressados em um turismo que é "menos a descoberta do outro, a relação física com o planeta, que um trajeto sonambólico guiado num mundo semi-fantasma de folclores e de monumentos" (Morin, 2000, p.69), mas preocupados com a sustentabilidade socioambiental dos locais visitados e com os saberes milenarmente acumulados, sabedorias de vida e valores éticos (Morin, 2000, p.65).

\section{Turismo e Sustentabilidade}

Foi, sobretudo, a partir da década de 1980 que o turismo começou a incorporar o conceito de sustentabilidade. O interesse aparentemente crescente das organizações do setor pelo turismo sustentável tem sido impulsionado pelo apoio de associações profissionais, pressão de grupos, tais como Tourism Concern, Green Flag, Campaign for Environmentally Responsible Tourism e alguns veículos da mídia (SWARBROOKE, 2000). No país, uma das primeiras publicações referenciais a abordar o tema foi "Ecologia, Cultura e Turismo" (1993), de Américo Pellegrini Filho.

De acordo com a Organização Mundial do Turismo (OMT, 1999), o turismo sustentável deve ser respeitoso com o meio ambiente, a valorização dos usos e costumes locais, a distribuição eqüitativa dos benefícios econômicos, sociais e culturais para as comunidades receptoras, bem como com os desejos e anseios do turista e a conservação dos patrimônios culturais. Observa- 


\section{TURISMO EM ANÁLISE}

se que o conceito de 'sustentável' tem, no entanto, muito a amadurecer, pois vem apresentando, freqüentemente, mais uma ação discursiva do que uma prática. Tanto o turismo, como outros setores, precisam oferecer respostas, em sua formação econômica, a essa questão.

Dentre as principais tendências no setor turístico, atualmente, que vão ao encontro da sustentabilidade, verificam-se a realização de pesquisas sobre métodos de gerenciamento da visitação e controle de impactos, como o Visitor Acitvity Management Process, entre outros (STIGLIANO, 2004); o desenvolvimento de normas técnicas e de certificação; o estabelecimento de Unidades de Conservação e seus respectivos Planos de manejo; a ampliação da educação patrimonial e a busca de profissionalização no setor.

O espaço físico, tanto o natural como o produzido, constitui a base do turismo, pois é onde se realizam as atividades turísticas, a concretização dos anseios dos visitantes. Como qualquer atividade humana, o turismo também gera efeitos sobre o ambiente onde se desenvolve. Estudar os efeitos da atividade turística em uma área, seja ela natural ou não, envolve a análise de diversos fatores que interferem nas modificações causadas pela utilização do local. O turismo gera, pois, muito dinamismo na organização espacial. Assim, a produção do espaço turístico concretiza-se pela interação contínua entre a configuração territorial dos espaços e suas relações sociais tomadas em dado momento (SANTOS, 1994). Os efeitos, ou impactos, resultantes da atividade devem ser avaliados em momentos distintos - entre o antes e o depois de sua ação modificadora. Autores como Butler (1999), Pérez de Las Heras (1999), Eagles e McCool (2002) os dividem em três categorias: econômicos, sócio-culturais e ambientais.

O turismo sustentável insere-se em um contexto em que alguns pesquisadores apontam, como tendência, o direcionamento do homem para um ciclo de novos valores: o valor do silêncio, da natureza, da solidariedade, dos laços entre as pessoas, cada vez mais distantes do homem pós-industrial. Segundo Boff (1994), assiste-se, também, ao retorno às experiências místicas e religiosas, frente à crise do paradigma civilizacional da contemporaneidade e à desilusão do paradigma racional da modernidade. $\mathrm{O}$ turista atual, assim, estaria mais propenso a ter maior interesse em vivenciar, em experimentar, não só o valor da natureza, mas o que existe de 


\section{TURISMO EM ANÁLISE}

diferencial na cultura local. Isto envolve, por exemplo, a gastronomia, as tradições, as edificações, as manifestações da relação homem/ambiente natural, em suma, a paisagem cultural.

Santos e Campos (2003) afirmam que os eixos básicos do desenvolvimento turístico sustentável - eqüidade social, eficiência econômica e conservação ambiental - devem ser concebidos como metas dos processos contínuos de mudança que orientam a participação da população na busca de formas adaptáveis às realidades locais, a fim de planejar e gerir qualitativamente a atividade turística. Assim, é fundamental, conforme Furlan (2003, p.57): "analisar o leque de transformações em curso, dentre elas dos novos valores morais e éticos em jogo, dos valores de uso da terra, da imposição de novas identidades".

Uma questão que se coloca é como impedir a concentração de benefícios, social e espacialmente. Levando-se em conta que o turismo pode reproduzir, tal como qualquer outro setor, as contradições dos processos de desenvolvimento, ressalta-se a pouca importância que tem sido dada à participação direta das comunidades nos projetos, planos e programas voltados ao seu desenvolvimento. Tal participação constitui uma oportunidade para se evitarem armadilhas de planejamentos forjados em gabinetes (LEROY, 1997), levando-se em conta que o turismo pode vir a ser uma atividade de sustentação de um novo modelo de desenvolvimento, em determinados locais.

A participação da comunidade deve ser uma importante estratégia para a consolidação do turismo sustentável em sua relação com a paisagem cultural. Além disso, é fundamental que se tenha dimensão sobre a potencialidade e o alcance da atividade turística, de como ela se integra no tecido social da região e dinamiza sua cultura. No processo de desenvolvimento local (GOTTARDO, 2002), é necessário, portanto, o apoio de lideranças preocupadas e orientadas para aspectos importantes da vida da comunidade. Um dos desafios a serem vencidos é tornar clara a opção pela atividade turística, como expressão do conjunto da comunidade, como fator de desenvolvimento local e regional, sabendo que muitas alterações, positivas e negativas, poderão ocorrer no cotidiano. A autonomia, assim, constitui um princípio ético e político que, uma vez assimilado, atribui a um grupo social em questão 


\section{TURISMO EM ANÁLISE}

possibilidades de escolha do turismo que se deseja (SOUZA, 1997). Faz-se relevante, desse modo, considerar que o turismo sustentável é um assunto político, daí versar sobre a distribuição de recursos. Refere-se, portanto, a quem detém o poder e como se utiliza dele. A participação comunitária remete, pois, à geração e distribuição de recursos na localidade, mas não somente. Diz respeito, sobremaneira, ao compartilhamento de conhecimento e à representatividade nas decisões de âmbito coletivo. A capacidade de tomar parte não pode apenas ser assegurada pelo direito a tal, os meios para se envolver são também necessários (JAMAL; GETZ, 1999). Entretanto, os caminhos para obter os recursos e habilidades necessários são comumente sujeitos aos governantes ou outros agentes, que, muitas vezes, não consideram os moradores locais como parceiros, mas como pessoas que devem estar submetidas a eles. Freqüentemente, os moradores locais, por sua vez, não sabem sequer por onde começar no que se refere à participação (JOPE, 1996).

Com relação ao envolvimento das comunidades locais, há que se atentar para o fato de que elas não são homogêneas ou têm um único ponto de vista sobre determinadas questões, o que faz com que haja necessidade de se desenvolverem mecanismos para arbitrar visões antagônicas. Além disso, na gestão do turismo é indesejável que minorias articuladas dominem o processo de decisão. O turismo envolve a elaboração de novos arranjos socioeconômicos e, nesse contexto, a inexperiência empresarial, a dificuldade de obtenção de financiamento e interesses conflitantes são alguns dos possíveis empecilhos, no nível local, que demandam atenção.

Os moradores locais fazem parte da formação das paisagens culturais, e, se não totalmente, ao menos potencialmente, também se relacionam com sua manutenção. Não se defende, portanto, uma visão "congelada" de preservação do patrimônio cultural e ambiental, dissociado das práticas humanas presentes. Destaca-se, pois, a importância do envolvimento dos grupos que residem em áreas de interesse pelo viés da paisagem cultural e seu potencial para evitar a massificação e homogeneização de destinos turísticos insustentáveis. 


\section{TURISMO EM ANÁLISE}

\section{Considerações Finais}

Algumas questões que vêm à tona no contexto analisado são: de que forma uma comunidade vê e se relaciona com determinada paisagem; e qual a visão do poder público e dos empresários locais sobre ela? É importante caminhar no sentido de elaborar propostas de intervenção que possibilitem o reconhecimento das singularidades do local. Tais ações podem vir a reforçar, nos grupos sociais envolvidos, o senso de identidade e de pertencimento, gerando reflexos positivos para a proteção de suas paisagens representativas e de suas culturas, ao meso tempo em que mantendo seus atrativos peculiares.

Pode-se pensar na paisagem cultural como atrativo para o turismo, ou como recurso para sua formulação. Tal posição é reforçada pela própria definição da UNESCO (1999), anteriormente citada. Na mesma linha, quando se aborda a ambiência, na Recomendação de Nairóbi (1976), remete-se ao contexto encontrado ao redor do bem protegido, o qual influi na percepção do observador. Diz respeito, entre outras coisas, à experiência que o visitante terá, ao que será observado e que deve, pois, refletir um cuidado interpretativo.

Uma das principais finalidades da definição de uma paisagem cultural tem relação com a intenção de que suas características primordiais sejam mantidas. Entre outras razões para tal está a intenção de propiciar que o referido patrimônio seja expressão de processos cognitivos, de atividades mentais, de trocas de informação, conhecimentos e de idéias. Como já mencionado, as relações dos homens com o meio ambiente e com o espaço nascem das sensações experimentadas e das percepções a elas ligadas (CLAVAL, 2001).

Assim sendo, neste artigo, relaciona-se o conceito de sustentabilidade ao de paisagem cultural, oferecendo subsídios para se pensar o turismo. Afinal, grande parte do que motiva as viagens são os patrimônios, fortemente definidos pela paisagem cultural. Não se espera esgotar a discussão, mas contribuir com subsídios para reflexões. Deste modo, elencam-se, a seguir, algumas das possíveis abordagens para futuras pesquisas e ações, visando uma maior sustentabilidade sócio-ambiental da atividade turística, com a valorização das paisagens culturais: aproximar os diversos grupos que compõem a sociedade local, valendo-se de técnicas como a história oral, por exemplo; identificar paisagens existentes - urbanas, industriais, naturais, rurais; relacionar tais paisagens a memórias e valores das comunidades 


\section{TURISMO EM ANÁLISE}

locais; considerar a visão local sobre a salvaguarda de práticas e remanescentes materiais; reconhecer as interfaces entre as ciências sociais, naturais e exatas nas ações a serem desenvolvidas; fortalecer a cooperação entre instituições que cuidam do patrimônio natural e histórico-cultural; melhorar o relacionamento dessas instituições com os grupos sociais que atendem, buscando aproximar suas posições, muitas vezes antagônicas; propiciar a criação de fóruns participativos para a tomada de decisões.

A valorização da paisagem cultural como patrimônio apresenta o potencial de trazer conseqüências diretas ao uso e à fruição comum do espaço por parte dos habitantes e dos visitantes. Valorizando aspectos espirituais, memoriais e afetivos relacionados às paisagens, otimizam-se esforços para o desenvolvimento de ações profícuas neste sentido.

Tal abordagem pode contribuir para o estabelecimento de políticas públicas de ordenamento e gestão territorial e, conseqüentemente, de formas mais sustentáveis de turismo. Naturalmente, faz-se, também, necessário, entre outras questões, contar com profissionais preparados para lidar com temas tão multidisciplinares e complexos como os abordados neste texto.

\section{Referências}

BERQUE, A. Paisagem-Marca, Paisagem-Matriz: Elementos da Problemática para uma Geografia Cultural. In: CORREAA, R.L.; ROSENDAHL, Z. (Orgs). Rio de Janeiro, EdUERJ, 1998. p.84-91.

BOFF, L. A nova era: civilização planetária. Rio de Janeiro: Editora Ática, 1994.

BUTLER, R.W. Understanding Tourism. In: JACKSON, E. L., BURTON, T.L. Leisure Studies Prospects for the Twenty-First Century. Pennsylvania: Venture, 1999. p. 97-101.

CLAVAL, P. A paisagem dos geógrafos. In: CORRÊA, R. L.; ROSENDAHL, Z. (orgs). Paisagens, textos e identidade. Rio de Janeiro: Ed. UERJ, 2004. p. 13-74.

CLAVAL, P. O papel da nova geografia cultural na compreensão da ação humana. In: CORRÊA, R. L; ROSENDAHL, Z. (orgs). Matrizes da geografia cultural. Rio de Janeiro: Ed. UERJ, 2001. p.35-86.

CLAVAL, P. A Geografia Cultural: o Estado da Arte. In: ROSENDAHL, Z.; CORRÊA, R.L. orgs). Manifestações da cultura no espaço. Rio de Janeiro: Ed. UERJ, 1999. p.59-98.

CORRÊA, R. L. Geografia cultural: passado e futuro - uma introdução. In: ROSENDAHL, Z; CORRÊA, R. L. (orgs). Manifestações da cultura no espaço. Rio de Janeiro: Ed. UERJ, 1999. p.4958.

CORREAA, R. L.; ROSENDAHL, Z. Apresentação. In: CORRÊA, R. L.; ROSENDAHL, Z. Geografia cultural: um século (1). Rio de Janeiro: EDUERJ, 2000. p. 7-14. 
COSGROVE, D. Geografia cultural do milênio. In: ROSENDAHL, Z.; CORRÊA, R. L. (orgs). Manifestações da cultura no espaço. Rio de Janeiro: Ed. UERJ, 1999. p.17-48.

COSGROVE, Denis. A geografia está em toda parte: cultura e simbolismo nas paisagens humanas. In: CORREAA, R.L.; ROSENDAHL, Z. (Orgs). Paisagem, tempo e cultura. $2^{\text {a }}$ ed. Rio de Janeiro: Ed. UERJ, 2004.

COSGROVE, Denis; JACKSON, Peter. Novos rumos da Geografia Cultural. In: ROSENDAHL, Z.; CORRÊA, R. L. Geografia cultural: um século (2). Rio de Janeiro: EDUERJ, 2000. p.15-32.

COUNCIL OF EUROPE. European Landscape Convention. European Treaty Series - No. 176. Florence, 2000.

DUNCAN, James S. Após a Guerra Civil: Reconstruindo a Geografia Cultural como heterotopia. In: ROSENDAHL, Z.; CORRÊA, R. L. Geografia cultural: um século (2). Rio de Janeiro: EDUERJ, 2000. p.61-84.

EAGLES, P.F.J.; McCOOL, S.F. Tourism in National Parks and Protected Areas - planning and management. Oxon: CABI Publishing, 2002.

FURLAN, S.A. Ecoturismo: do sujeito ecológico ao consumidor da natureza. In: RODRIGUES, A.B. (org.) Ecoturismo no Brasil: possibilidades e limites. Sao Paulo: Contexto, 2003. p. 47-58.

GOTTARDO, L. C. Desenvolvimento e Turismo Sustentável - um desafio, uma necessidade. In: SOUZA, M. J. de. Políticas Públicas e o lugar do turismo. Brasília: UNB/MMA, 2002, 3v. p. 193-206.

HOLZER, W. Paisagem, Imaginário, Identidade: alternativas para o estudo geográfico. In: ROSENDAHL, Z.; CORRÊA, R. L. (Org.). Manifestações da Cultura no Espaço. Rio de Janeiro: EDUERJ, 1999. p. 149-168.

IPHAN. Carta de Bagé ou Carta da Paisagem Cultural. Disponível em $<$ http://portal.iphan.gov.br/portal/>. Acesso em: 12 de agosto de 2008.

JAMAL, T.B; GETZ, D. Community roundtables for tourism-related conflicts: the dialectics of consensus and process structures. Journal of Sustainable Tourism, vol.7, n.3-4, p.290-313, 1999.

JOPE, M. Sustainable community tourism development revisited. Tourism Management vol. 17, n.7, p.475-479, 1996.

LEROY, J-P. Da comunidade local às dinâmicas microrregionais na busca do desenvolvimento sustentável. In: BECKER. B.; MIRANDA, M. (orgs.). A geografia política do desenvolvimento sustentável. Rio de Janeiro: Editora da UFRJ, 1997.

MERQUIOR, José Guilherme. O véu e a mascara: ensaios sobre cultural e ideologia. São Paulo: T.A. Queiroz Editor, 1997.

MIKESELL, Marvin W. Posfácio: Novos interesses, problemas não resolvidos e tarefas que persistem. In: CORRÊA, R. L.; ROSENDAHL, Z. (Orgs.) Geografia cultural: um século (2). Rio de Janeiro: EDUERJ, 2000. p.85-109.

MILANI, R. El arte del paisaje. Madrid: Editorial Biblioteca Nueva, 2007.

MORIN, E. ; KERN, A.B. Terra Pátria. Lisboa: Instituto Piaget, 2000.

OMT - Organização Mundial do Turismo. Guia para administraciones locales: desarollo turístico sostenible. Madrid: OMT, 1999. 
PELLEGRINI FILHO, Américo. Ecologia, cultural e turismo. Campinas: Papirus, 1993.

PÉREZ DE LAS HERAS, M. La Guía del Ecoturismo - o cómo conservar la naturaleza a través del turismo. Espanha: Ediciones Mundi-Prensa, 1999.

RELPH, E. Place and Placelessness. Londres: Pion, 1976.

RIBEIRO, R. W. Paisagem cultural e patrimônio. Rio de Janeiro: IPHAN, 2007.

SANTOS, M. Metamorfoses do espaço habitado. 3. ed. São Paulo: Hucitec, 1994.

SANTOS, C. A. de J.; CAMPOS, A. C. Estratégias para o desenvolvimento sustentável do turismo. In: CORIOLANO, L. N. M. T.; LIMA, L. C. Turismo comunitário e responsabilidade socioambiental. Fortaleza: EDUECE, 2003.

SAUER, Carl O. Desenvolvimentos recentes em Geografia Cultural. In: CORRÊA, R. L.; ROSENDAHL, Z.; (Orgs.) Geografia cultural: um século (1). Rio de Janeiro: EDUERJ, 2000. p. 1598.

SCHAMA, S. Paisagem e memória. Tradução Hildegard Feist. São Paulo: Companhia das Letras, 1996.

SOUZA, M. J. L. De. Como pode o turismo contribuir para o desenvolvimento local? In: RODRIGUES, A. B. (Org.) Turismo - desenvolvimento local. São Paulo: HUCITEC, 1997.

STIGLIANO, B. V. Visitantes em Unidades de Conservação: o método VAMP aplicado ao Parque Estadual de Campos do Jordão (SP). 2004. (Mestrado em Ciências da Comunicação) - Escola de Comunicações e Artes da Universidade de São Paulo, São Paulo, 2004.

STIGLIANO, B. V. Participação comunitária e sustentabilidade socioambiental do turismo na vila ferroviária de Paranapiacaba, S.P. 2009. (Doutorado em Ciência Ambiental) - Programa de PósGraduação em Ciência Ambiental da Universidade de São Paulo, São Paulo, 2009.

SWARBROOKE, J. Turismo sustentável - conceitos e impacto ambiental. São Paulo: Aleph, 2000.

TUAN, Y.F. Topofilia: um estudo da percepção, atitudes e valores do meio ambiente. Tradução de Livia de Oliveira. São Paulo: DIFEL, 1980.

TUAN, Y. F. Espaço e lugar: a perspectiva da experiência. Tradução de Lívia de Oliveira. São Paulo: Difel, 1983.

UNESCO. Operational Guidelines for the Implementation of the World Heritage Convention. Paris: World Heritage Centre, WHC/92, revised March 1999.

WAGNER, Philip L.; MIKESELL, Marvin W. Temas da Geografia cultural. In: CORRÊA, R. L.; ROSENDAHL, Z. (Orgs.) Geografia cultural: um século (1). Rio de Janeiro: EDUERJ, 2000. p. 111167.

\section{Recebido em: 11/03/2011}

Aprovado em: 25/04/2011 (1 ${ }^{\mathrm{a}}$ versão) 03/07/2011 ( $2^{\mathrm{a}}$ versão) 